\title{
The Development of Chlamydia trachomatis Inclusions within the Host Eukaryotic Cell during Interphase and Mitosis
}

\author{
By STEVEN CAMPBELL, SHIRLEY J. RICHMOND* AND PETER YATES \\ The Department of Medical Microbiology, Medical School, University of Manchester, \\ Oxford Road, Manchester MI3 9PT, UK
}

(Received 2 December 1988; revised 24 January 1989; accepted 6 February 1989)

\begin{abstract}
The dynamic nature of Chlamydia trachomatis inclusions was studied by video and $35 \mathrm{~mm}$ timelapse photomicrography of live cells, and by immunolocalization of inclusions in fixed cells. A serotype $\mathrm{E}$ isolate was used to infect the McCoy cell line and endometrial epithelia. Then resulting inclusions were observed over $4 \mathrm{~d}$. They appeared as slowly expanding fluid-filled membrane vesicles whose growth varied considerably, and which were subject to great physical distortion by the host cell during interphase and mitosis. When this distortion became extreme the inclusion was observed to divide. However, as inclusions were mobile within the cytoplasm and thus able to come into contact with each other, there was a net tendency for the opposite process of inclusion fusion to occur when cells contained more than one inclusion. The proportion of infected cells decreased with time as a result of host cell proliferation, despite transmission of inclusions to progeny at the time of mitosis. Inclusion growth physically disrupted karyokinesis and cytokinesis so that host cell division became distorted or blocked on the second or third day of infection. Cell death eventually occurred by a very rapid lysis event.
\end{abstract}

\section{INTRODUCTION}

The interaction of the intracellular chlamydial parasite with its host cell is a complex phenomenon that allows parasite growth and survival of the host cell population. The consequence of this evolutionary balancing act is the development of a persistent and often asymptomatic infection which nevertheless can have serious long-term sequelae for the infected host (Paavonnen, 1988). The target for infection by genital strains of Chlamydia trachomatis is the epithelial cells which line the mucosal surfaces of the urogenital tracts (Swanson et al., 1975). Chlamydial elementary bodies (EBs) first interact with the host by binding to the surface (Kaul et al., 1987; Hodinka et al., 1988). Subsequent endocytosis results in their incorporation into membrane-bound cytoplasmic vesicles (Hodinka et al., 1988). Some of these chlamydial vesicles fuse with lysosomes (Pearce \& Prain, 1986; Prain \& Pearce, 1985), which leads to chlamydial destruction. When lysosomal fusion does not occur the EB within the vesicle differentiates into a reticulate body (RB) which then begins to proliferate. This proliferation is associated with a vast increase in the size of the chlamydial endosome, or inclusion (Evans, 1972), which occurs even when host protein synthesis is poisoned by cycloheximide (Ripa \& Mardh, 1977). As the inclusion grows the progeny RBs condense back into EBs to yield between $10^{2}$ and $10^{3}$ viable organisms per infected eukaryotic cell (Stirling \& Richmond, 1977). After three to four days of growth in vitro, when the inclusions occupy most of the host cell cytoplasm, cell lysis occurs and a new generation of infectious EBs are released. During the course of one infection cycle the host cell may undergo division (Horoschak \& Moulder, 1978; Bose \& Liebhaber, 1979) which leads to

Abbreviations: EB, elementary body; RB, reticulate body; IFU, inclusion forming units.

Terminology: 'cell' refers exclusively to the eukaryotic host. 
the production of a mosaic of infected and uninfected progeny even if initially all host cells contain inclusions.

In this study we have examined the growth of a genital strain of $C$. trachomatis (serotype E) by time-lapse photography of living cells and fluorescent immunolocalization of inclusions after fixation. We have attempted to quantify and characterize inclusion growth and development and to examine the effects that the inclusion has on the infected host cell, particularly its effect on the process of cell division. Two cell systems were used because of their complementary characteristics. (a) The transformed McCoy fibroblast line which supported chlamydial growth whilst continuing to proliferate rapidly. (b) Human endometrial explant cultures; these produced cell sheets which migrated over the substratum and so mimicked the regenerative phase of the menstrual cycle in vivo (Campbell et al., 1988).

\section{METHODS}

Chlamydiae. High-titre stocks of C. trachomatis serotype E strain T181 (Sompolinsky \& Richmond, 1974) were prepared and titrated in McCoy cells as previously described (Richmond, 1985) except that no cycloheximide was used to inhibit host cell growth. Organisms were presented to host cells by centrifugation $\left(2000 \mathrm{~g}\right.$ at $34^{\circ} \mathrm{C}$ for $30 \mathrm{~min}$ ), then the inoculating medium was replaced with fresh medium and incubation and video recording commenced.

Cell culture. McCoy cells were passaged routinely from local stocks. Currettings of human endometrium were made available by Dr Peter Haynes, with the approval of the local ethical committee. The currettings were dissociated with collagenase and hyaluronidase, and glandular fragments purified by selective filtration and centrifugation (Campbell et al., 1988).

The growth medium used for epithelial cells was a 1:1 mixture of Dulbecco's Modified Eagle's Medium and Ham's F-12 growth medium with 15 mM-HEPES buffer (Sigma). It was supplemented with $10 \%$ (w/v) foetal calf serum, $14 \mathrm{~mm}$-sodium bicarbonate, $10 \mathrm{ng}$ epidermal growth factor $\mathrm{ml}^{-1}$ (Collaborative Research), $5 \mu \mathrm{g}$ insulin $\mathrm{ml}^{-1}$ (Sigma), $10^{-7} \mathrm{M}$-hydrocortisone (Sigma), $2 \mathrm{mM}$-glutamine, $50 \mu \mathrm{g}$ vancomycin $\mathrm{ml}^{-1}$ and $100 \mu \mathrm{g}$ streptomycin $\mathrm{ml}^{-1}$. McCoy cells were cultured in the same medium except that no growth factor or hormones were used to supplement the medium. The cells or glandular fragments were plated into collagen-coated (Campbell et al., 1988) glass-bottomed flasks (Allen, 1987) and infected immediately before recording was started. All observations on living cells were made before $96 \mathrm{~h}$ of culture.

Time-lapse photography. Intermittent $35 \mathrm{~mm}$ time-lapse sequences were made with a long working distance $\times 40$ phase objective fitted to an inverted phase microscope (TMS, Nikon) placed in a $37^{\circ} \mathrm{C}$ hot room. A 35 mm camera body (OM2 spot, Olympus) fitted with a data back and power winder was attached to one of the binocular eyepieces. The microscope lamp and motor wind were switched on and off automatically with a microcomputer (Vic 20) and a relay system. These sequences were recorded on Technical Pan film (Kodak) rated at 64 ASA and developed for high contrast in D76 (Kodak) $1+1$ dilution for $11 \mathrm{~min}$ at $20^{\circ} \mathrm{C}$. Video time-lapse sequences were recorded with the same objective lens fitted to a trinocular inverted microscope (Diavert, Leitz). The cells were continuously illuminated with a low-intensity red light and observed with a 1 inch ER Newvicon camera (National Panasonic). The sequences were timed with a video timer (VT 12, Four-A, Tokyo) and recorded with a U-format VCR (6650E, JVC), with reduced back tension, at a fixed lapse rate of approximately $7 \mathrm{~s}$. Unfortunately the restricted horizontal width of the field $(320 \mu \mathrm{m})$ required to achieve good resolution with the video system made it difficult to follow individual motile cells over long periods and simultaneously to view the internal contents of the inclusion. Still images from the video sequences were photographed onto monochrome film (T-Max, Kodak) and developed for pictorial contrast.

Quantitative analysis of inclusion shape. Analysis of inclusion shape in live infected cells was made directly from video tape. The video signal was processed by a timebase corrector/frame store (CEL Ltd) and a video enhancer (Detailer IV, Vidicraft). Analysis was carried out with a semi-automatic microcomputer based system (Measure Mouse, Analytical Measuring Systems). Measurements were made on a subsidiary screen by tracing the outline of the inclusions over the frozen video image with a mouse.

Immunolocalization of C. trachomatis. McCoy cells were plated into slide flasks (Nunclon) at a density of $25000 \mathrm{~cm}^{-2}$ and infected the next day as described above. The infected cells were fixed at selected times over a $3 \mathrm{~d}$ period with $2 \%(\mathrm{v} / \mathrm{v})$ formaldehyde for $20 \mathrm{~min}$, then permeabilized with ethanol at room temperature and immediately stained. Inclusions were identified with a rabbit polyclonal antiserum to chlamydiae and a fluorescein isothiocyanate (FITC)-conjugated anti-rabbit antiserum. The cells were counterstained with rhodamine phalloidin (Molecular Probes, Eugene, USA) in order to identify the filamentous actin within the cytokinetic furrows of cells which had proceeded successfully through mitosis. Randomly selected microscope fields were examined with a $\times 63$ planapochromat phase lens and the number of inclusions in each cell 
determined. Endometrial cultures were fixed in industrial-grade ethanol. Infected mitotic epithelial cells were identified with an anti-cytokeratin monoclonal antibody (Sanbio) and a tetramethylrhodamine isothiocyanate (TRITC)-conjugated goat anti-mouse immunoglobulin (Zymed), and stained for inclusions as indicated above.

\section{RESULTS}

The view of the inclusion presented here is a composite one produced by analysis of more than $2000 \mathrm{~h}$ (elapsed time) of video time-lapse films, 30 intermittent stills sequences, live video recording of numerous fields and analysis of fixed cells at selected times throughout the period of inclusion growth. The total number of inclusions observed by time-lapse was very small in comparison with inclusions examined in fixed cells at single points in time. The observations are presented thematically and where indicated draw upon more than one culture system.

\section{Inclusion growth}

Early inclusions were traced retrospectively in McCoy cells because they were immobile enough for some of them to remain within the field of observation throughout the course of inclusion development. Inclusions were first detectable as small phase bright vesicles $12-16 \mathrm{~h}$ after the start of centrifugation.

These early inclusions moved in a saltatory fashion within the host cell cytoplasm in a way that was indistinguishable from that of small cellular vesicles. The growth of the inclusion was followed by measuring its cross-sectional area in a plane parallel to the substratum at several time points. Two sorts of analysis were undertaken: individual inclusions were followed over a prolonged period by time-lapse microscopy, and additionally many thousands of cells were videoed at selected times so that distribution of inclusion size could be described. Comparison of individual inclusions within McCoy cells demonstrated that the growth rate and initial lag period varied from one host cell to another (Fig. 1). This resulted in a great diversity of inclusion size within the population of infected cells during the course of inclusion development (Fig. 2). Toward the end of the third day of incubation a second cycle of inclusion formation was suggested by the bimodal distribution (Fig. 2d).

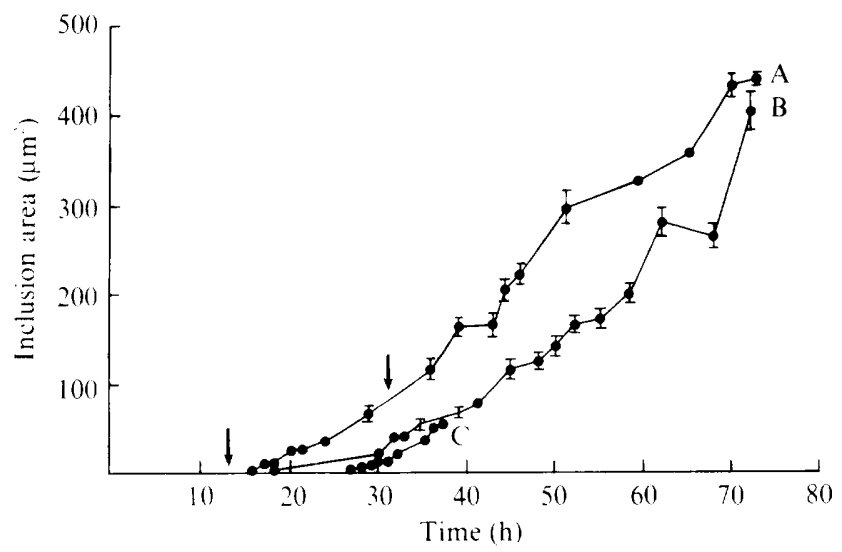

Fig. 1. Three growth curves of individual inclusions in separate McCoy cells. The arrows indicate the times at which the host cell (A) underwent a successful mitotic division. At the beginning and end of the period of measurement the inclusions were almost circular in outline (form factor data not shown). The irregularity in growth of cross-sectional area (A, B) was at least partly due to deviation of inclusion shape from circularity in a plane perpendicular to the optical axis or due to changes in inclusion orientation within the host cell. The initial lag phase varied from cell to cell although the reason for this has not yet been established (C). Error bars represent the standard deviation of ten repeat measurements. 

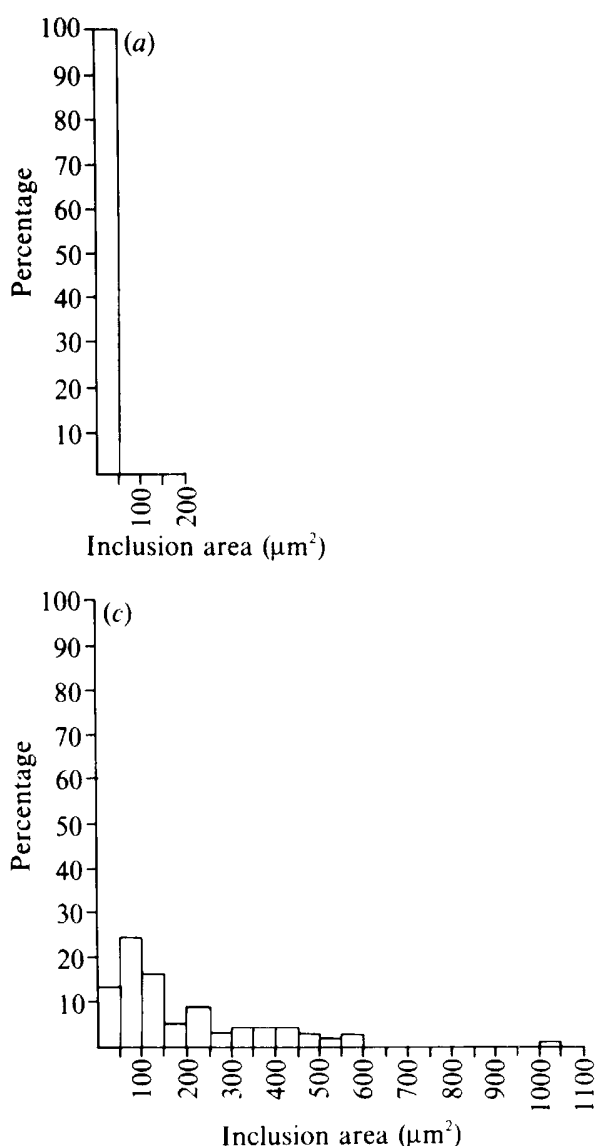
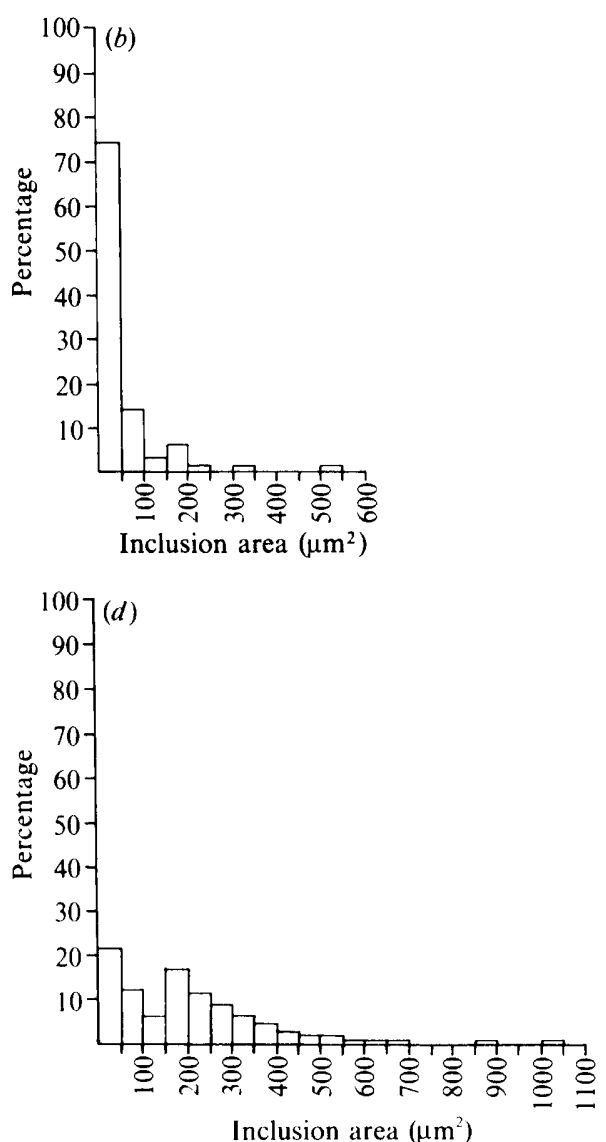

Fig. 2. Distribution of cross-sectional area of inclusions in living McCoy cells made from 'live' video recordings at selected times $(a, 20 \mathrm{~h} ; b, 40 \mathrm{~h} ; c, 64 \mathrm{~h} ; d, 71 \mathrm{~h})$. One hundred inclusions were measured per time point. The inoculum was chosen to minimize multiple infection (approx. 1 cell in 8 infected at $40 \mathrm{~h}$ ). However, the giant cells which occurred infrequently in these cultures were more likely to be multiply infected because of their greatly increased target area. Inclusion fusion within these cells gave rise to the large inclusions which occurred at low frequency within histograms $(b),(c)$ and $(d)$. The area distribution of the remaining inclusions was surprisingly wide, and may be accounted for by different lag times and growth rates in different host cells.

\section{Inclusion fusion}

The frequency of very large inclusions was increased when the inoculum was adjusted to yield more than one inclusion in some cells (Fig. 3). This was probably due to the tendency of inclusions in multiply infected cells to fuse. Inclusion fusion, which has previously been inferred by light (Evans, 1972; Blyth \& Taverne, 1972) and electron microscopy (Hodinka et al., 1988) was observed directly in both McCoy and endometrial cells with both forms of time-lapse microscopy. Fusion of both small and large inclusions was observed during interphase (Fig. 4) and mitosis (Fig. 5) of the host cell. In some cases fusion occurred very soon after close approach of the two vesicles. On other occasions inclusions remained in close contact without fusing for many hours. The actual fusion events were rapid when they occurred and led to the formation of a new inclusion shape within a few minutes. The number of inclusions observed per fixed cell declined significantly with time so that by $48 \mathrm{~h}$ it was highly probable that there was only one inclusion in each infected cell (Table 1). This was a consequence of both inclusion fusion and host cell division, which caused a redistribution of inclusions to both progeny. From these 


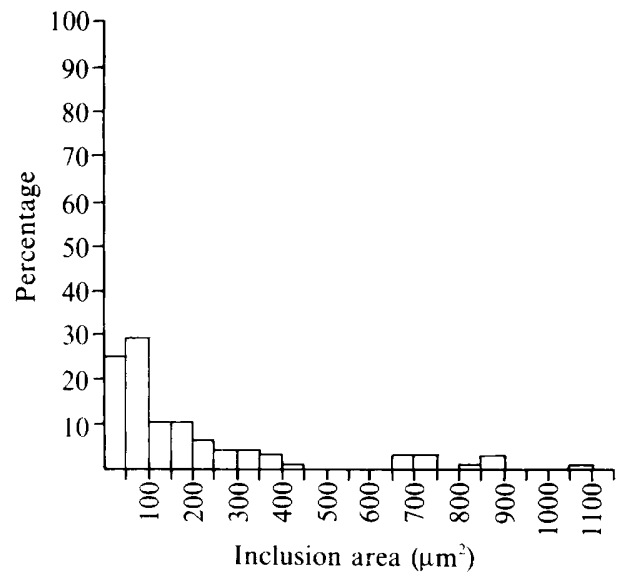

Fig. 3. Distribution of cross-sectional area of inclusions in live cells after $40 \mathrm{~h}$ at a higher multiplicity of infection than Fig. $2(b)$ (approx. 1 cell in 3 infected at $40 \mathrm{~h}$ ). Inclusion area tended to be greater at this inoculum due to inclusion fusion in both normal and giant cells.
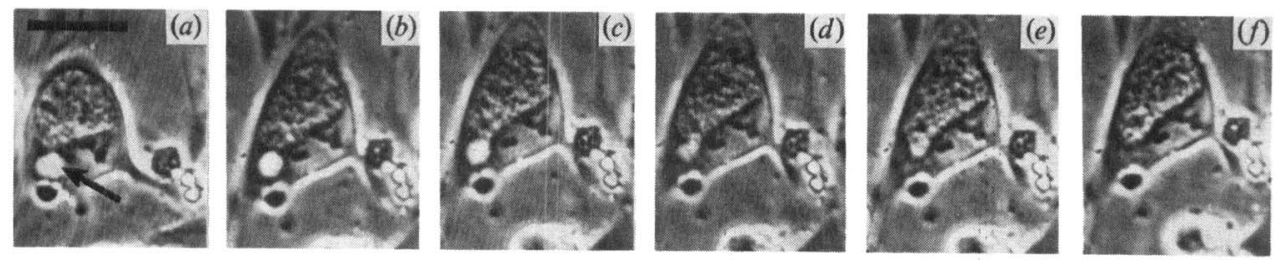

Fig. 4. A motile endometrial epithelial cell $44 \mathrm{~h}$ after infection in which a small inclusion (arrow) is seen fusing with a much larger one over the course of a few minutes. Interval time between frames: $(a)$ to $(b), 15 \mathrm{~min} ;(b)$ to $(c), 6 \mathrm{~min} ;(c)$ to $(d), 33 \mathrm{~s} ;(d)$ to $(e), 1 \mathrm{~min} 15 \mathrm{~s} ;(e)$ to $(f), 7 \mathrm{~min}$. Bar, $56 \mu \mathrm{m}$.

Table 1. Decline in the number of inclusions per cell with time

\begin{tabular}{ccccc} 
& \multicolumn{4}{c}{$\begin{array}{c}\text { Percentage of cells* containing more than } \\
\text { one inclusion at: }\end{array}$} \\
\cline { 2 - 5 } Inoculum & $20 \mathrm{~h}$ & $30.7 \mathrm{~h}$ & $42 \mathrm{~h}$ & $53.5 \mathrm{~h}$ \\
$2.5 \times 10^{5} \mathrm{IFU} \mathrm{cm}$ c $^{-2}$ & 24.7 & 0.9 & 0.2 & 0.0 \\
$5 \times 10^{4} \mathrm{IFU} \mathrm{cm}^{-2}$ & 12.4 & 2.9 & 0.0 & 0.0
\end{tabular}

* A mean of 256 cells were counted per data point.

measurements we have concluded that in heavily infected relatively immobile proliferating cells the net tendency is for inclusion fusion to occur.

\section{Inclusion pleomorphism and division}

Inclusions underwent rapid changes of shape particularly when the host cell was also changing shape. Pleomorphism was therefore particularly pronounced in the migratory endometrial epithelium, where cells often changed shape during the course of locomotion. However, the consequences of inclusion shape change were harder to follow in the latter cells as they tended to leave the field of observation. In one particularly dramatic sequence the change of inclusion shape, induced by cell movement, became so extreme that the inclusion divided into two parts (Fig. 6), as originally predicted when fixed cells were examined (Richmond, 1985). 

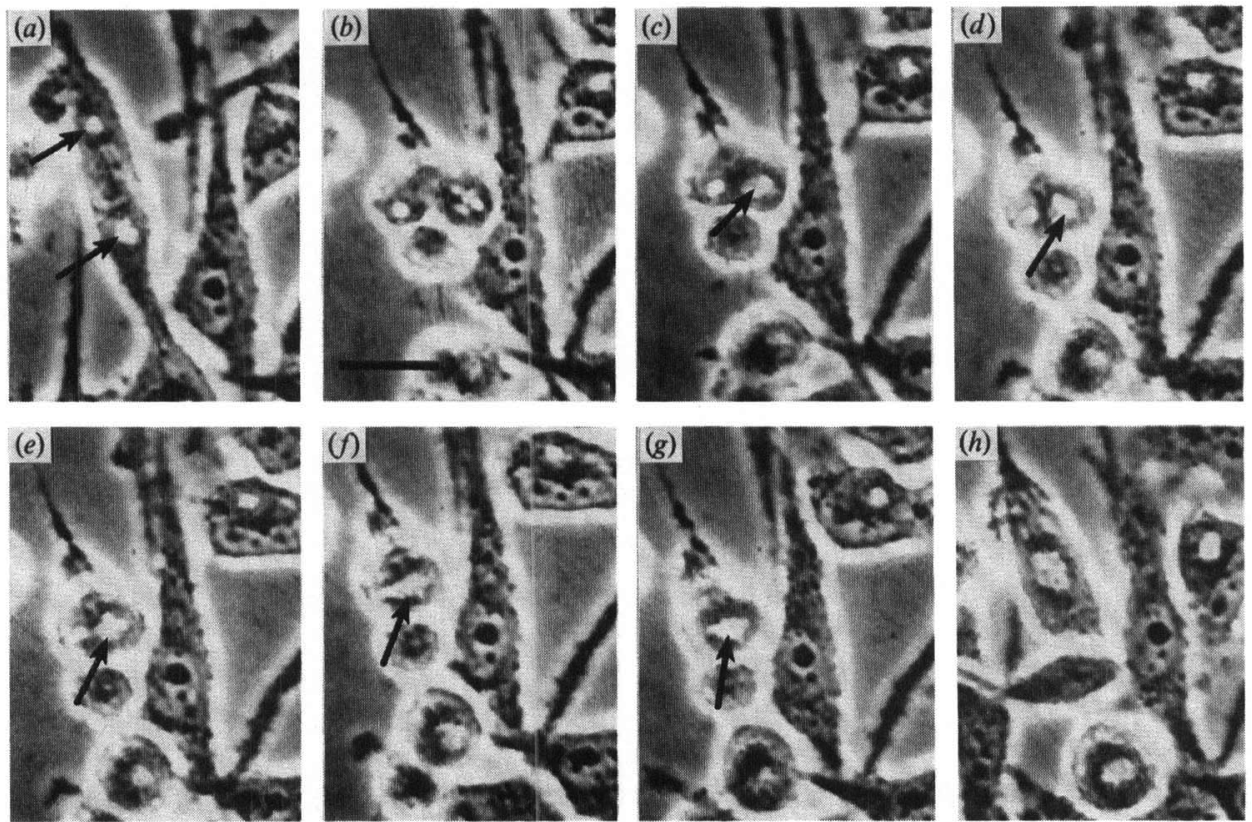

Fig. 5. A McCoy cell $24 \mathrm{~h}$ after infection, with two perinuclear inclusions ( $a$, arrows). The cell entered mitosis $(b)$, which became distorted due to the presence of inclusions. Cytokinesis proceeded and both inclusions fused ( $c$ to $g$, arrow). The daughter cells then respread $(h)$; only one was infected after division. It was initially larger in area than the uninfected cell due to the distortion of cell division. Interval time between frames: $(a)$ to $(b), 140 \mathrm{~min} ;(b)$ to $(c), 8 \mathrm{~min} ;(c)$ to $(d), 10 \mathrm{~min} ;(d)$ to $(e), 1 \mathrm{~min} ;(e)$ to $(f), 2 \mathrm{~min} ;(f)$ to $(g), 18 \mathrm{~min} ;(g)$ to $(h), 105 \mathrm{~min}$. Bar, $36 \mu \mathrm{m}$.
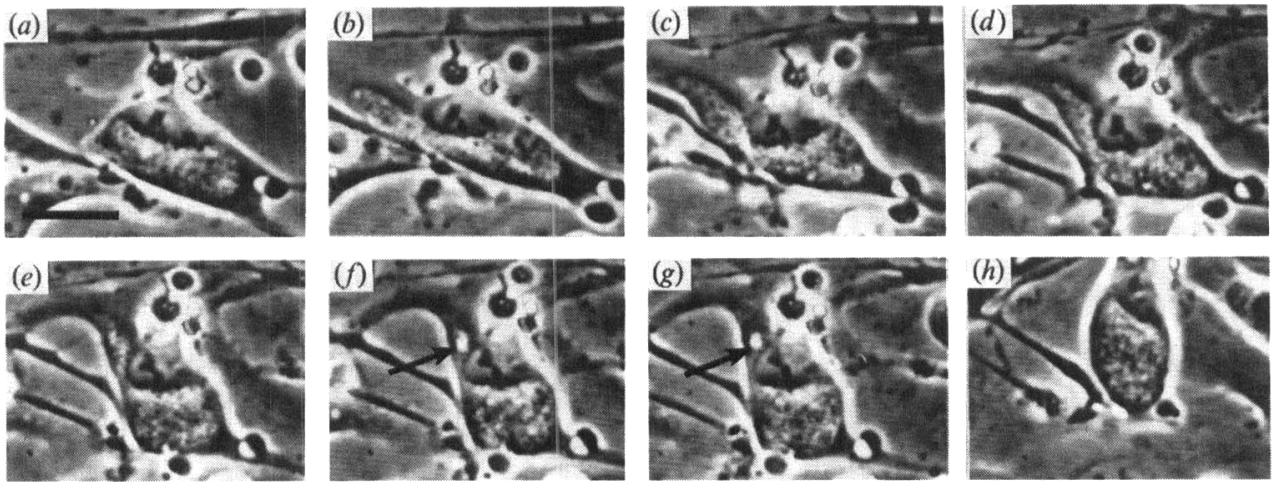

Fig. 6. An endometrial epithelial cell contained one large inclusion (a) which bulged into a thin lamellipodium $(b)$. The cell changed shape causing the inclusion to bend around the nucleus $(c$ to $e$ ). This process became so extreme that a little inclusion (arrow) was pinched off $(f, g)$. The cell then migrated from the field of observation $(h)$. Interval time between frames: $(a)$ to $(b), 41 \mathrm{~min} ;(b)$ to $(c), 34 \mathrm{~min} ;(c)$ to $(d), 21 \mathrm{~min} ;(d)$ to $(e), 8 \mathrm{~min} ;(e)$ to $(f), 3 \mathrm{~min} ;(f)$ to $(g), 10 \mathrm{~min} ;(g)$ to $(h), 82 \mathrm{~min}$. $\mathrm{Bar}, 60 \mu \mathrm{m}$.

\section{The fluid nature of the inclusion and the development of discontinuities within it}

The major features which identified live inclusions when they were viewed by phase microscopy was the presence of small phase-dark particles in constant Brownian motion. In order to undergo such movement the organisms must be within a fluid environment. During the second or third day of the chlamydial growth cycle, discontinuities developed within the inclusions (Fig. 7) and were particularly obvious in endometrial epithelial cells. These areas, 

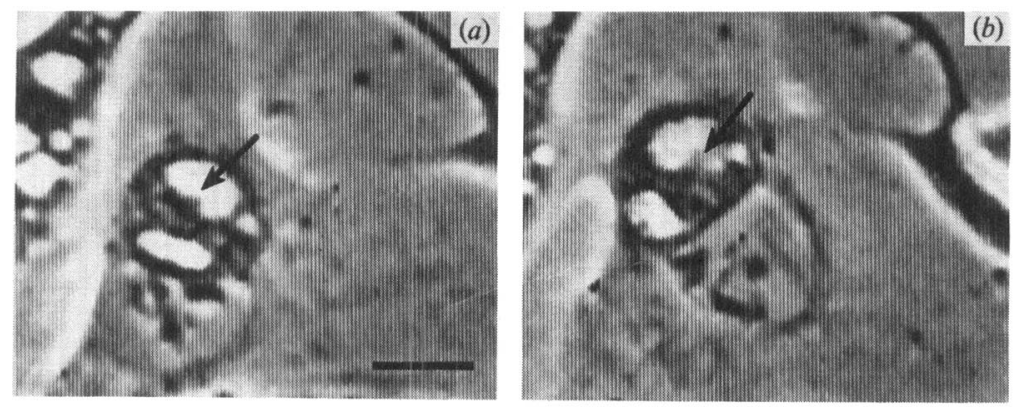

Fig. 7. Part of an endometrial epithelial cell showing a perinuclear inclusion. The internal phase-bright areas of the inclusion (arrows) were devoid of particle movement. These areas changed morphology rapidly and partially fused with each other $(b$, arrow). Interval time from $(a)$ to $(b), 5 \mathrm{~min}$. Bar, $23 \mu \mathrm{m}$.
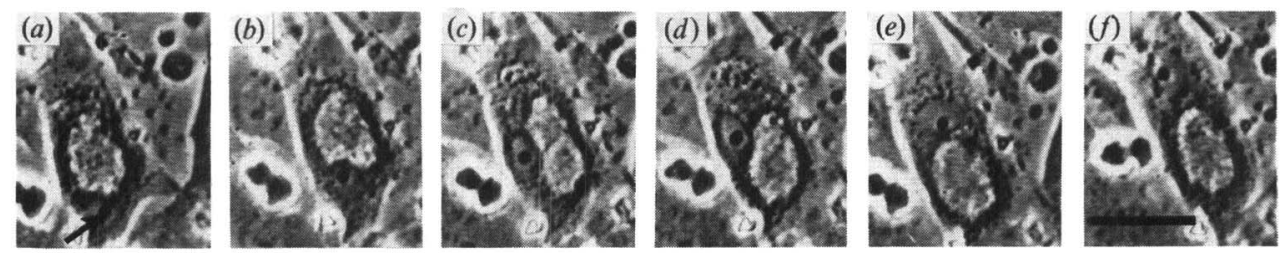

Fig. 8. A temporarily immotile endometrial epithelial cell containing one large perinuclear inclusion on the third day of infection $(a)$. The nucleus (arrow) moved rapidly along one edge of the inclusion over the course of $9 \mathrm{~min}$, distorting the shape of the inclusion as it did so $(b$ to $d)$. Upon reaching the other side of the inclusion the nucleus moved away from it. Interval time between frames : $(a)$ to $(b), 10 \mathrm{~min}$; $(b)$ to $(c), 4 \mathrm{~min} ;(c)$ to $(d), 1 \mathrm{~min} 40 \mathrm{~s} ;(d)$ to $(e), 4 \mathrm{~min} 20 \mathrm{~s} ;(e)$ to $(f), 7 \mathrm{~min}$. Bar, $60 \mu \mathrm{m}$.

which were devoid of particle movement, varied greatly in size, distribution and profile, having either discrete edges or ill-defined boundaries. These were presumed to be membrane vesicles or nultilamellar bodies. These structures moved around within the inclusions and were observed to fuse or coalesce with each other. However, it was not clear if they fused with the inclusion membrane and thus acted as a reservoir of membrane for inclusion growth.

\section{Inclusion mobility within the cytoplasm}

Movement of inclusions within the cytoplasm facilitated the fusion events described above. In cells which contained only one inclusion, mobility was most easily detected as relative movement with respect to the nucleus. Within the highly motile endometrial cells the position as well as the shape of the inclusion varied throughout the course of inclusion enlargement. Considerable relative movement between the nucleus and inclusion was observed in spite of the tendency of inclusions to adopt a perinuclear position (Fig. 7) and sometimes the inclusion moved completely around the nucleus or vice versa. In one sequence the nucleus actually deformed the inclusion as it moved past (Fig. 8); a period of relative nuclear-inclusion movement then occurred in which each structure moved while the other appeared stationary. The most bizarre event observed by time-lapse microscopy was nuclear rotation (Paddock \& Albrecht-Beuhler, 1986a,b). This happened within infected and uninfected endometrial and McCoy cells at various times throughout interphase, and it was apparently unimpeded by the presence of a closely apposed inclusion. These phenomena suggested to us that the perinuclear location of inclusions that is frequently observed in fixed cells represents a minimum-energy conformation to which the system will return after perturbation, rather than a fixed link between nucleus and inclusion. 
Table 2. Decline in the proportion of infected cells with time

\begin{tabular}{|c|c|c|c|c|}
\hline \multirow[b]{2}{*}{ Inoculum } & \multicolumn{4}{|c|}{$\begin{array}{l}\text { Percentage of cells* containing one or } \\
\text { more inclusions at: }\end{array}$} \\
\hline & $20 \mathrm{~h}$ & $30 \cdot 7 \mathrm{~h}$ & $42 \mathrm{~h}$ & $53.5 \mathrm{~h}$ \\
\hline $2.5 \times 10^{5} \mathrm{IFU} \mathrm{\textrm {cm } ^ { - 2 }}$ & $58 \cdot 9$ & $46 \cdot 7$ & $38 \cdot 7$ & $36 \cdot 0$ \\
\hline $5 \times 10^{4}$ IFU cm-2 & $22 \cdot 6$ & $16 \cdot 8$ & $12 \cdot 1$ & 7.9 \\
\hline $1 \times 10^{4} \mathrm{IFU} \mathrm{cm}-2$ & $9 \cdot 2$ & $6 \cdot 2$ & $4 \cdot 2$ & $2 \cdot 2$ \\
\hline
\end{tabular}

* A mean of 1069 cells were counted per data point.

\section{Host cell division}

The mobility and deformability of inclusions allowed infected cells to undergo the shape changes and reorganization associated with mitosis, at least in the earlier stages of inclusion development. Within proliferating populations of McCoy cells the proportion that were infected declined with time, even when many cells were multiply infected and thus were capable of redistributing their inclusions to both progeny (Table 2). This was associated with a gradual decrease in the proportion of infected mitotic cells which proceeded successfully through cytokinesis, so that by the third day of infection only a very small proportion of mitoses resulted in the transmission of inclusions to daughter cells. (The percentage of infected cells in late mitosis recorded in one experiment declined as follows: $24 \mathrm{~h} 53.6 \%, 40 \mathrm{~h} 36 \cdot 1 \% ; 48 \mathrm{~h} 12.2 \%$; $65 \mathrm{~h} 1 \%$. A mean of 76 late mitoses were counted per data point.)

Qualitative observations on living infected cells demonstrated three possible outcomes of mitosis which revealed the underlying mechanisms responsible for the quantitative data. (a) Successful mitoses, in which cell division appeared to proceed unimpeded by the presence of one or more inclusions, were observed during the first $48 \mathrm{~h}$ of inclusion development. When only one inclusion was present one daughter cell inherited the inclusion whilst the other reverted to an apparently normal uninfected state. Both daughters in this situation were then able to produce new progeny (Fig. 9), as described previously in HeLa cells infected with the L2 serotype of C. trachomatis (Bose \& Liebhaber, 1979). When there was more than one inclusion within a cell, sometimes both daughters inherited an inclusion; on other occasions only one daughter was infected (Fig. 5). Similar successful mitoses and inclusion distributions were observed at the edges of infected keratin-stained endometrial epithelial cell sheets when cell division started after $48 \mathrm{~h}$ in culture. (b) Abnormal mitoses, in which both karyokinesis (chromosome movement) and/or cytokinesis (pinching off of the cytoplasm) were distorted, were observed during the second day of infection. This resulted sometimes in divisions where one of the progeny was larger than the other. (c) Failure of mitosis due to blockage of mitosis after karyokinesis was seen after $36 \mathrm{~h}$ of infection. In the example shown in Fig. 10 a cytokinetic furrow formed in the cell at the site of the displaced metaphase spindle but did not develop where the inclusion was interposed between the spindle and cell surface (Rappaport, 1986). This led to failure of cytokinesis and formation of a binucleate cell. All of these observations suggest that the presence of an inclusion within a mitotic cell has a range of effects which are dependent on the physical size of the inclusion.

\section{Events late in the infection cycle}

At this stage, when the inclusions became highly distended, severe disruption of cell organization occurred. The best example of this was seen in an endometrial cell where an inclusion herniated into a sac which continuously changed morphology in an apparently uncontrolled fashion for several hours prior to lysis (Fig. 11). Host cell lysis in McCoy cells (Fig. 12) was consistent with the loss of inclusion integrity observed by electron microscopy (Stirling \& Richmond, 1977; Todd \& Caldwell, 1985; Doughri et al., 1972). However, the resolution of the optical system and the complexity of the phase image did not allow us to confirm the existence of chlamydial exocytosis without host cell lysis (Todd \& Caldwell, 1985). An internal lysis event occurred in which the inclusion burst very rapidly (i.e. within one time-lapse cycle of 


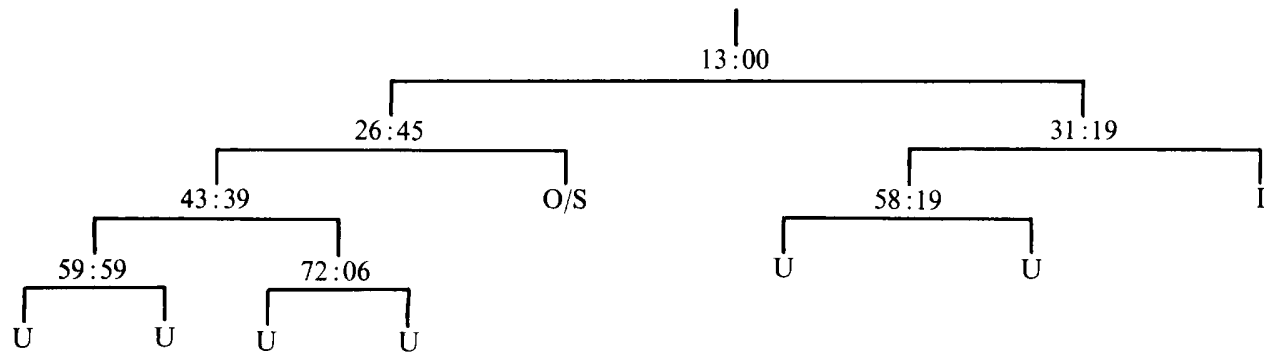

Fig. 9. The most extensive pedigree obtained by video time-lapse recording of McCoy cell cultures over a $72 \mathrm{~h}$ period. One infected cell present within the field of observation at the beginning of recording produced at least six progeny with no detectable inclusions and one which contained a large inclusion at the end of recording. The numbers denote the total time in hours from the start of centrifugation. I, inclusion containing cell; $\mathrm{U}$, uninfected cells; $\mathrm{O} / \mathrm{S}$, cell migrated off screen.
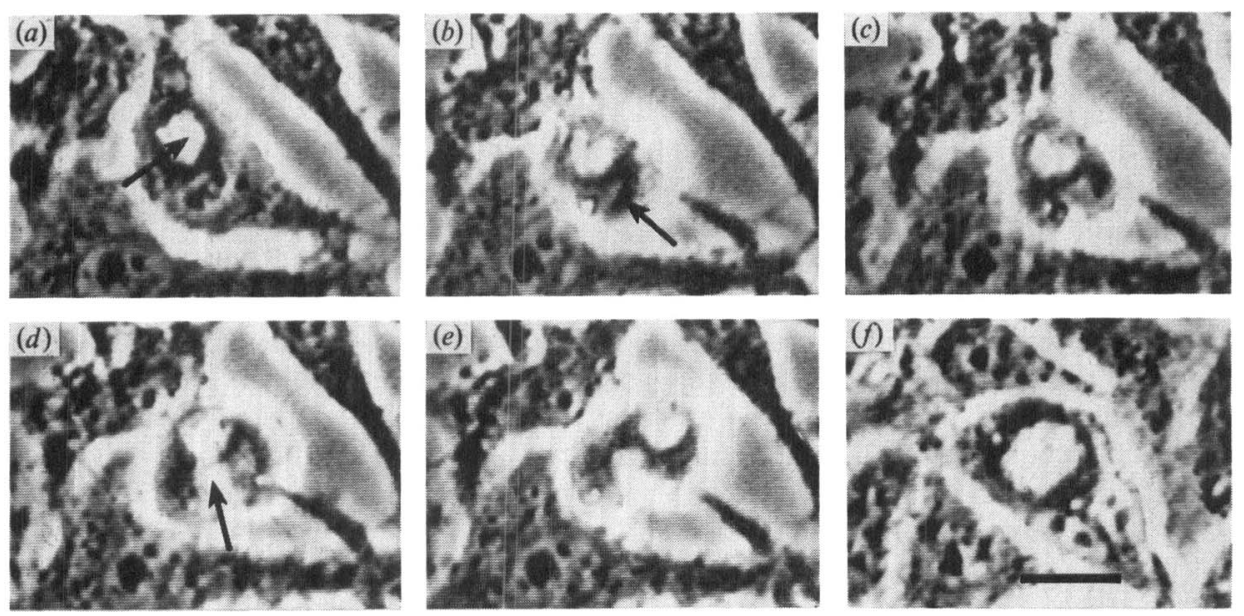

Fig. 10. A McCoy cell containing one inclusion (arrow) $36 \mathrm{~h}$ after infection (a) rounded up to enter mitosis. The chromosomes aligned along the metaphase plate ( $b$, arrow) which was displaced to one side due to the presence of the inclusion. The chromosomes moved rapidly apart at the appropriate time at an apparently normal speed although in an eccentric position $(c)$. Separation of the daughter cells was inhibited by the presence of the inclusion in the cytokinetic furrow ( $d$, arrow). One set of chromosomes moved through the failing cytokinetic furrow as the cytoplasm of the left-hand daughter was resorbed into the right hand cell $(e)$, giving rise to a binucleate cell $(f)$. Interval time between frames: $(a)$ to $(b)$, $90 \mathrm{~min} ;(b)$ to $(c), 4 \mathrm{~min} ;(c)$ to $(d), 14 \mathrm{~min} ;(d)$ to $(e), 9 \mathrm{~min} ;(e)$ to $(f), 11 \mathrm{~h} 41 \mathrm{~min}$. Bar, $39 \mu \mathrm{m}$.
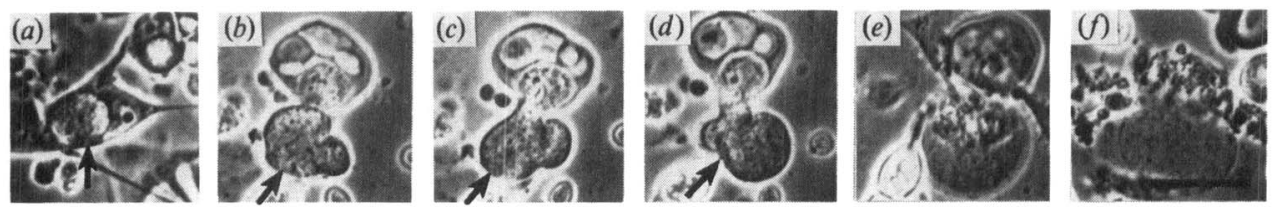

Fig. 11. An endometrial epithelial cell containing a large inclusion (arrow) $3 \mathrm{~d}$ after infection (a). During the next day the inclusion herniated into a sac which changed morphology in a random and apparently uncontrolled fashion ( $b$ to $d$, arrow). An internal lysis event then disrupted the cell even further $(e)$ producing a membrane bubble which was stable for at least $6 \mathrm{~h}$. $(f)$ Interval time between frames: $(a)$ to $(b), 24.5 \mathrm{~h} ;(b)$ to $(c), 15 \mathrm{~min} ;(c)$ to $(d), 8 \mathrm{~min} ;(d)$ to $(e), 11 \mathrm{~h} ;(e)$ to $(f), 8 \mathrm{~h}$. Bar, $85 \mu \mathrm{m}$. 

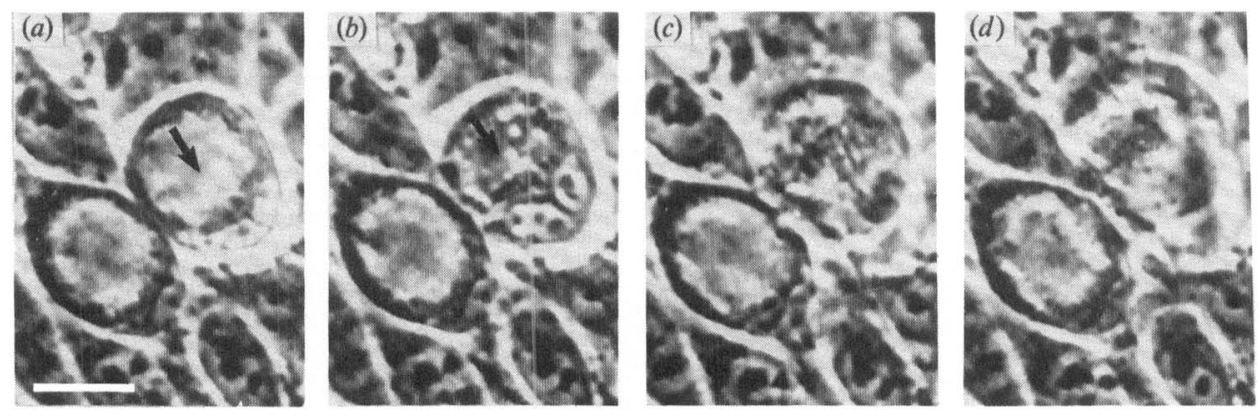

Fig. 12. After $72 \mathrm{~h}$ of incubation one of two adjacent infected McCoy cells underwent a very rapid internal lysis ( $a, b$ arrow), followed by further internal disruption which obliterated the nuclei $(c)$ and caused complete cellular disorganization $(d)$. Interval time between frames: $(a)$ to $(b), 7 \mathrm{~s} ;(b)$ to $(c)$, $9 \mathrm{~min} ;(c)$ to $(d), 15 \mathrm{~min}$. Bar, $35 \mu \mathrm{m}$.

$7 \mathrm{~s})$. This was followed by a disruption of cytoplasmic organization during the next few minutes. Cell lysis then followed rapidly and was accompanied by a diffusion of chlamydiae away from the site of the infected cell. On occasions cell death produced tethered or floating spherical membrane bubbles (Fig. 11) which probably contained cell contents as well as chlamydiae (Doughri et al., 1972). These appeared remarkably stable and were found within the field of observation for up to $6 \mathrm{~h}$. Membrane bubble formation was not a pattern of death unique to chlamydia-infected cells but was also observed in uninfected epithelial cells. The alternative pattern of cell death involved disruption of cell organization before inclusion lysis (data not shown). In one sequence from an endometrial culture disruption of the cell spread as a wave from one end to the other and engulfed a small inclusion so that inclusion and cell lysis occurred almost simultaneously. In this case cell death was not directly attributable to the presence of a distended chlamydial inclusion, but seemed to occur for other reasons. Such events may be particularly relevant to natural infections of the human endometrium where cell death occurs on a regular basis as a consequence of menstruation.

\section{DISCUSSION}

The picture of the C. trachomatis inclusion presented here complements the accepted view of chlamydial development at the cellular level (Ward, 1983) by dynamically illustrating inclusion growth and the background of cellular activity which occurs during the chlamydial growth cycle.

The time-lapse sequences shown demonstrate the remarkable plasticity of the host eukaryotic cell. Despite the existence of a large aberrant vesicle cell adhesion can be maintained, chromosomal replication may occur, cells can enter mitosis, and their progeny respread after mitosis has been successfully completed, provided the inclusion does not become too large. However, our observations suggest that the presence of very large inclusions during the second and third days of infection physically disrupts the organization of the host cell so that mitosis is no longer possible.

Chlamydia psittaci (strain 6BC) was shown to inhibit the division of mouse fibroblasts in a colony-forming assay (Horoschak \& Moulder, 1978), thus supporting the conclusions of the present work. Unfortunately the non-refractile phase-dark appearance of the more densely packed 6BC inclusions makes them more difficult to study by time-lapse microscopy (S. C., unpublished observations). Moreover, inclusions of different biotypes may not exert the same effect on the host cell, since great variation in inclusion morphology exists between strains (Spears \& Stortz, 1979). For example, chlamydiae which form lobulate inclusions such as 6BC may undergo inclusion division more readily, and cause a different pattern of host cell disruption from the quasi-spherical inclusions of $C$. trachomatis. 
In another time-lapse study the presence of $C$. trachomatis inclusions (serotype L2) in HeLa cells did not influence the timing of host cell division in those cells which had successfully divided (Bose \& Liebhaber, 1979). However, these authors, who used a time-lapse interval approximately 40 times longer than that used here, did not describe the very rapid events revealed in this study. It is clear from our work that during the early period of infection, when there is no apparent block of division, it is valid to equate division with progression into S-phase (Bose \& Liebhaber, 1979). However, this does not apply later in the infection cycle when chromosome replication can occur even although cytokinesis may be blocked. Furthermore, if only successful mitoses are analysed by time-lapse, then the inhibitory effects of inclusion growth which we have described would go undetected.

The observations presented here and in the previous time-lapse study (Bose \& Liebhaber, 1979) suggest to us that chlamydiae do not directly interfere with host control of the cell cycle in vitro. The early chlamydial inclusion appears to be well tolerated by the host cell in vitro during the early stages of a low-multiplicity infection (Horoschak \& Moulder, 1978). We therefore predict that restriction of key amino acids (Allan \& Pearce, 1983) by agents such as interferon (Byrne \& Krueger, 1983; Byrne et al., 1986, 1988; de la Maza et al., 1987), and chlamydiostatic antibiotics such as $\beta$-lactams (Ridgeway et al., 1978), which limit inclusion size in vitro, will delay or inhibit the disruptive effects produced by large inclusions.

Direct extrapolation of our work to the in vivo situation is probably most relevant to situations where the total number of target cells is increasing, as in the endometrial epithelium during the proliferative phase of the human menstrual cycle (Demopolos, 1982). Although the situation in vivo may differ quantitatively from the cultured cell populations we have studied here (e.g. in the rate of both host cell proliferation and inclusion growth, and in the inclusion size which disrupts columnar epithelial cell function and causes cell lysis), nevertheless our findings are likely to be qualitatively relevant to the situation in vivo.

Spread of extracellular EBs at the mucosal surface after host cell lysis is an additional important factor to consider in vivo. Local retention of EBs on the extracellular matrix (Campbell et al., 1988) or in the mucus bathing the apical surface of cells could produce a locally high concentration of EBs and thus lead to multiple infection and rapid growth of inclusions due to inclusion fusion. Paradoxically this would not be the most effective means of amplification of the infection. Although inclusions formed by fusion rapidly generate a large number of infectious EBs the total yield of organisms is likely to be greatest when the infected cell lysate is widely distributed to many cells (Evans, 1972). In Fallopian tube infection the stirring activity of the ciliated cells may distribute chlamydiae throughout the tubes, leading to efficiently disseminated infection. Lysis of an infected cell within a mucus-filled gland of the secretoryphase endometrium may provide conditions more suitable for multiple infection because there are fewer ciliated cells in this tissue (Masterson et al., 1975).

The precise mechanism of host cell lysis is also important in vivo. If cells form membrane bubbles of the kind observed here then the next generation of EBs will be temporarily restricted from making contact with other host cells, as well as being subjected to the damaging effect of lysosomal enzymes which one would expect to be decompartmentalized at the time of host cell disruption.

Host cell destruction in vitro is paralleled by the disruption of tissue architecture that occurs in chronic severe infection in vivo (Gump et al., 1981; Paavonnen et al., 1985). Such disruptions of cell function may be caused by release of soluble antigens from infected cells (Richmond \& Stirling, 1981; Stuart et al., 1987) which could cause toxic or immune-mediated damage (Taylor et al., 1987). Either of these two pathogenic mechanisms would be likely to cause more widely disseminated effects than local cell killing due to inclusion lysis observed in this study.

This work was supported by an MRC project grant to S. J. R., and by generous assistance from the Zochonis Trust and the Kershaw Trust. 


\section{REFERENCES}

Allan, I. \& Pearce, J. H. (1983). Amino acid requirements of strains of Chlamydia trachomatis and Chlamydia psittaci growing in McCoy cells: relationship with clinical syndrome and host origin. Journal of General Microbiology 129, 2001-2007.

Allen, T. D. (1987). Time-lapse video microscopy using an animation control unit. Journal of Microscopy 147, 129-135.

Bose, S. K. \& Liebhaber, J. (1979). Deoxyribonucleic acid synthesis, cell cycle progression, and division of chlamydia-infected HeLa 229 cells. Infection and Immunity 24, 953-957.

Blyth, W. A. \& Taverne, J. (1972). Some consequences of the multiple infection of cell cultures by TRIC organisms. Journal of Hygiene 70, 33-37.

ByrNe, G. \& KRUEGER, D. (1983). Lymphokinemediated inhibition of Chlamydia psittaci replication in mouse fibroblasts is neutralised by anti-gamma interferon immunoglobulin. Infection and Immunity 42, $1152-1158$.

Byrne, G., Lehmann, L. \& Landry, G. (1986). Induction of tryptophan catabolism is the mechanism for gamma-interferon-mediated inhibition of intracellular Chlamydia psittaci replication in T24 cells. Infection \& Immunity 53, 347--351.

Byrne, G., Williams, D. M., Schobert, C. S. \& Krueger, D. A. (1988). Persistent infections and the immune response to Chlamydiae. In Proceedings of the European Society for Chlamydia Research vol. 1, pp. 113-116. Bologna: Societa Editrice Esculapio.

CAMPBell, S., Richmond, S. J., Haynes, P., Gump, D., YATES, P. \& ALLEN, T. D. (1988). An in vitro model of Chlamydia trachomatis infection in the regenerative phase of the human menstrual cycle. Journal of General Microbiology 134, 2077-2087.

DEMOPOLOS, R. J. (1982). Normal endometrium. In Pathology of the Female Genital Tract, 2nd edn, pp. 235-278. Edited by A. Blaustien. Berlin: Springer.

Doughri, A. M., Storz, J. \& Altera, K. P. (1972). Mode of entry and release of chlamydiae in infections of intestinal epithelial cells. Journal of Infectious Diseases 126, 652-657.

Evans, A. (1972). The development of TRIC organisms in cell cultures during multiple infection. Journal of Hygiene 70, 39-49.

Gump, D. W., Dickstien, S. \& Gibson, M. (1981). Endometritis related to Chlamydia trachomatis infection. Annals of Internal Medicine 95, 61-63.

Hodinka, R. L., Davis, C. L., ChOONG, J. \& WYRICK, P. B. (1988). Ultrastructural study of endocytosis of Chlamydia trachomatis McCoy cells. Infection and Immunity 56, 1456-1463.

HoRoschaK, K. D. \& Moulder, J. W. (1978). Division of single host cells after infection with Chlamydiae. Infection and Immunity 19, 281-286.

Kaul, R., Roy, K. L. \& Wenman, W. M. (1987). Cloning, expression, and structure of a Chlamydia trachomatis binding protein. Journal of Bacteriology 169, 5152-5166.

Masterson, R., Armstrong, E. M. \& More, I. A. E. (1975). The cyclical variation in the percentage of ciliated cells in the normal human endometrium. Journal of Reproduction and Fertility 42, 537-540. de la Maza, L. M., Peterson, E. M., Burton, L. E., Gray, P. W., RinderkNECHT, E. \& CZARNIECKI, C. W. (1987). The antichlamydial, antiviral, and antiproliferative activities of human gamma interferon are dependent on the integrity of the $\mathrm{C}$ terminus of the interferon molecule. Infection and Immunity 55, $2727-2733$

PaAvonnen, J. (1988). Clinical manifestations and therapy of genital infections in women. In Proceedings of the European Society for Chlamydial Research vol. 1, pp. 153-155. Bologna: Societa Editrice Esculapio.

Paavonnen, J., Aine, R., Teilsa, K., Heinonen, P. K., Punnonen, R., Lehtinen, M., Miettinen, A. \& Gronroos, P. (1985). Chlamydial endometritis. Journal of Clinical Pathology 38, 726-732.

PADDOCK, S. W. \& AlBRecht-BuEhler, G. (1986a). Distribution of microfilament bundles during rotation of the nucleus in 3T3 cells treated with monensin. Experimental Cell Research 163, 525-538.

Paddock, S. W. \& Albrecht-Buehler, G. (1986 b). The degree of coupling of nuclear rotation in binucleate 3T3 cells. Experimental Cell Research 166 , 113-126.

Pearce, J. H. \& Prain, C. J. (1986). Intracellular association of Chlamydia psittaci with lysosomes during infection of McCoy cells. In Chlamydial Infections, pp. 43-46. Edited by D. Oriel, D. Ridgeway, J. Schachter, D. Taylor-Robinson \& M. Ward. London: Cambridge University Press.

Prain, C. J. \& Pearce, J. H. (1985). Endocytosis of chlamydia by McCoy cells: measurement and effects of centrifugation. FEMS Microbiology Letters 26, 233-237.

RAPPAPORT, P. (1986). The establishment of the mechanism of cytokinesis in animal cells. International Review of Cytology 105, 245-281.

RICHMOND, S. J. (1985). Division and transmission of inclusions of Chlamydia trachomatis in replicating McCoy monolayers. FEMS Microbiology Letters 29, 49-52.

Richmond, S. J. \& STIRLING, S. (1981). Localisation of chlamydial group antigen in McCoy cell monolayers infected with Chlamydia trachomatis or Chlamydia psittaci. Infection and Immunity 34, 561-570.

Ridgeway, G. L., OWEN, J. M. \& ORIEL, J. D. (1978). The antimicrobial susceptibility of Chlamydia trachomatis in cell culture. British Journal of Venereal Diseases 54, 103-106.

RIPA, K. T. \& MARDH, P. (1977). Cultivation of Chlamydia trachomatis in cycloheximide treated McCoy cells. Journal of Clinical Microbiology 6, 328331

SOMPOLINSKY, D. \& RiCHMOND, S. J. (1974). Growth of Chlamydia trachomatis in McCoy cells treated with cytochalasin B. Applied Microbiology 28, 912-914.

SPEARS, P. \& Stortz, J. (1979). Biotyping of Chlamydia psittaci based on inclusion morphology and response to diethylaminoethyl-Dextran and Cycloheximide. Infection and Immunity 24, 224-232.

StIRLING, P. \& Richmond, S. J. (1977). The developmental cycle of Chlamydia trachomatis in McCoy cells treated with cytochalasin B. Journal of General Microbiology 100, 31-42. 
Stuart, E. S., Tirrell, S. M. \& Macdonald, A. B. (1987). Characterisation of an antigen secreted by chlamydia-infected cell culture Immunology 61, 527533.

Swanson, J., Eschenbach, D. A., Alexander, E. R. \& Holmes, K. K. (1975). Light and electron microscope study of Chlamydia trachomatis infection in the uterine cervix. Journal of Infectious Diseases 131, 678-687.

TAYLOR, H. R., JohNSON, S. L., SChachter, J., Caldwell, H. D. \& Prendergast, R. A. (1987).
Pathogenesis of trachoma: the stimulus for inflammation. Journal of Immunology 138, 3023-3027.

Todd, W. J. \& Caldwell, H. D. (1985). The interaction of Chlamydia trachomatis with host cells: ultrastructural studies of the mechanism of release of a biovar II strain from HeLa 229 cells. Journal of Infectious Diseases 151, 1037-1044.

WARD, M. E. (1983). Chlamydial classification, development and structure. British Medical Bulletin 39, 109-155. 